\title{
SIGNIFICANDO A VIOLÊNCIA OBSTÉTRICA FRENTE ÀS FORMAÇÕES MÉDICA E JURÍDICA: ERRO MÉDICO OU VIOLÊNCIA DE GÊNERO?
}

\author{
Maiane Cibele de Mesquita Serra* \\ Adriano Carvalho Viana**
}

\begin{abstract}
RESUMO
A violência obstétrica ou violência institucional na atenção obstétrica caracteriza-se como qualquer intervenção desnecessária e ou iatrogênica ou ainda sem o consentimento da parturiente perpetrada por profissionais de saúde, bem como pelas instituições (públicas e privadas) durante a gravidez, o parto e pós-parto, desrespeitando a autonomia da mulher em dispor sobre o próprio corpo e sexualidade. A partir de uma metodologia, de caráter exploratório, do tipo qualitativo, envolvendo pesquisa bibliográfica, objetivou-se correlacionar o tema com as formações médica e jurídica de modo a propor reflexões à sociedade, em especial, aos agentes do sistema de saúde, aos agentes dos sistemas de justiça, e às parturientes com relação ao fenômeno.
\end{abstract}

Palavras-chave: Violência obstétrica; Gênero. Violência de gênero. Formação médica. Formação jurídica.

\begin{abstract}
Obstetric violence or institutional violence in obstetric care is characterized as any unnecessary and or iatrogenic intervention or an intervention imposed without the consent of the parturient perpetrated by health professionals, as well as by institutions (public and private) during pregnancy, childbirth and postpartum, disrespecting the autonomy of women to dispose of their own body and sexuality. Based on an exploratory methodology of the qualitative type, involving bibliographical research, the objective was to correlate the subject with the medical and legal formations in order to propose reflections to society, especially to the agents of the health system, to the agents of justice systems, and to parturients about the phenomenon.
\end{abstract}

Keywords: Obstetric violence. Gender. Gender violence. Parturients. Power. Medical formation. Legal formation.

\section{INTRODUÇÃO}

\footnotetext{
*Mestre em Direito e Instituições do Sistema de Justiça, do Programa de Pós-Graduação em Direito da Universidade Federal do Maranhão (PPGDIR/UFMA). Especialista em Docência na Educação Profissional e Tecnológica pelo SENAI CETIQT. Graduada em Direito pela Faculdade Santa Terezinha - CEST. Advogada pela OAB/MA. Licenciada em Letras - Português/Inglês pela Universidade Federal do Maranhão. Professora da Faculdade Santa Terezinha - CEST e Faculdade Pitágoras. Contato: maianeserra@hotmail.com

** Mestrando em Letras pela Universidade Federal do Maranhão. Graduado em Filosofia pelo Centro Universitário Assunção. Graduando em Direito pela Faculdade Santa Terezinha- CEST. Graduando em Teologia pela Faculdade Uninter de Curitiba- Conveniada com a Faculdade Católica de Curitiba.
} 
A violência obstétrica é uma forma de violência de gênero e de violência institucional imbricada por relações de poder, sendo caracterizada pela apropriação do corpo e dos processos reprodutivos da mulher parturiente pelos profissionais de saúde, mediante um tratamento desumanizado, abuso de medicalização e patologização dos processos naturais do parto. Tal modalidade de violência constitui-se como uma violação dos direitos fundamentais, direitos humanos e também de princípios constitucionais e bioéticos uma vez que impõe a perda de autonomia e também da capacidade da mulher de decidir livremente sobre seu corpo e sobre sua sexualidade, culminando em consequências negativas e desastrosas para a qualidade de vida das que foram acometidas por violência obstétrica.

A Convenção Interamericana para Prevenir, Punir e Erradicar a Violência contra a Mulher, também conhecida como "Convenção de Belém do Pará”, define a violência contra a mulher no seu art. $1^{\circ}$ como: "qualquer ato ou conduta baseada no gênero, que cause morte, dano ou sofrimento físico, sexual ou psicológico à mulher, tanto na esfera pública como na esfera privada".

A violência obstétrica classificada como uma violência de gênero e violência institucional baseia-se nos padrões estereotipados de comportamento e costumes sociais e culturais, dispensados à mulher parturiente, justamente em virtude da construção histórica e cultural falocêntrica, desrespeitando a autonomia da mulher em dispor sobre o seu corpo e sexualidade, ferindo sua integridade física e psíquica.

A pesquisa "Mulheres brasileiras e gênero nos espaços público e privado", realizada pela Fundação Perseu Abramo em 2010, alcançou notoriedade nacional ao dispor sobre um problema de saúde pública silente e invisibilizada: a violência no parto. Atestou-se que $25 \%$ das mulheres que tiveram partos normais (nas redes pública e privada) sofreram algum tipo de maus-tratos e desrespeito durante o trabalho de parto, parto e/ou pós-parto imediato. Os dados colhidos promoveram discussões acerca da problemática, disseminando pesquisas acadêmicas e divulgando importantes ações dos movimentos de mulheres no que diz respeito ao enfrentamento da temática em questão. (VENTURI; GODINHO, 2010)

Nesse sentido, convém mencionar que a jurisprudência do STF e STJ têm amparado questões relativas à violência obstétrica sob o escopo de "erro médico", conforme pesquisa realizada por Silva e Serra (2017) analisando acórdãos entre 2007 e 2016.

Sob esse enfoque, percebe-se que a violência obstétrica se correlaciona com as questões inerentes à prática médica, bem como à forma como as demandas têm sido (des)tratadas na esfera jurídica, contribuindo para invisibilidade do fenômeno, razão pela qual se objetiva 
discutir a partir do presente artigo as formações médica e jurídica em busca dos fatores etiológicos possíveis para explicar a desumanização crescente que caracteriza o exercício laboral dos médicos e operadores do direito frente ao objeto de pesquisa do presente estudo.

Objetiva-se ainda, a partir das discussões empreendidas, trazer conhecimento e propor reflexões à sociedade, em especial, aos agentes do sistema de saúde, aos agentes dos sistemas de justiça e às parturientes, em relação ao fenômeno em questão. A fim de alcançar os objetivos propostos, utilizou-se uma metodologia de caráter exploratório, do tipo qualitativo, envolvendo pesquisa bibliográfica.

\title{
2 A VIOLÊNCIA OBSTÉTRICA COMO VIOLÊNCIA DE GÊNERO
}

Esta modalidade de violência caracteriza-se pela apropriação do corpo e dos processos reprodutivos da mulher pelos agentes de saúde, mediante um tratamento desumanizado, abuso de medicalização e patologização dos processos naturais, causando a perda de autonomia da parturiente e da capacidade de decidir livremente sobre seu corpo e sexualidade, o que pode culminar em consequências negativas e desastrosas para a qualidade de vida. ${ }^{1}$

Segundo a OMS (1996; 2014), muitas das intervenções aplicadas rotineiramente são na verdade consideradas como fatores de risco tanto para a mulher quanto para o neonato. Ademais, as crenças e os preconceitos no que concerne à sexualidade e saúde das mulheres em uma sociedade tipicamente patriarcal contribuem sobremaneira na forma como elas são percebidas e (des)tratadas pelos profissionais. Ademais, a violência obstétrica é fortemente condicionada por preconceitos de gênero. Consoante Aguiar:

\begin{abstract}
Estes maus-tratos vividos pelas pacientes, na maioria das vezes, segundo alguns autores, encontram-se relacionados a práticas discriminatórias por parte dos profissionais, quanto a gênero, entrelaçados com discriminação de classe social e etnia, subjacentes à permanência de uma ideologia que naturaliza a condição social de reprodutora da mulher como seu destino biológico, e marca uma inferioridade física e moral da mulher que permite que seu corpo e sua sexualidade sejam objetos de controle da sociedade através da prática médica. (2010, p. 15).
\end{abstract}

No segundo semestre de 2014, a OMS se pronunciou a respeito da temática, publicando em seis idiomas uma declaração acerca da violência obstétrica, exigindo políticas e promoção à assistência obstétrica humanizada, além da adoção de medidas governamentais no

\footnotetext{
${ }^{1}$ Definição dada pelas leis venezuelana e argentina, nas quais a violência obstétrica é tipificada: Lei Orgânica sobre o Direito das Mulheres a uma Vida Livre de Violência, de novembro de 2007 e Lei Nacional $n^{\circ} 26.485$, de Proteção Integral para Prevenir, Punir e Erradicar a Violência contra as Mulheres nos Âmbitos em que se Desenvolvem suas Relações Interpessoais, vigente na Argentina desde 2009, respectivamente.
} 
sentido de abolir o desrespeito e abuso contra as mulheres durante o parto. Segundo a Organização:

\begin{abstract}
Todas as mulheres têm direito ao mais alto padrão de saúde atingível, incluindo o direito a uma assistência digna e respeitosa durante toda a gravidez e o parto, assim como o direito de estar livre da violência e discriminação. Os abusos, os maus-tratos, a negligência e o desrespeito durante o parto equivalem a uma violação dos direitos humanos fundamentais das mulheres, como descrevem as normas e princípios de direitos humanos adotados internacionalmente. Em especial, as mulheres grávidas têm o direito de serem iguais em dignidade, de serem livres para procurar, receber e dar informações, de não sofrerem discriminações e de usufruírem do mais alto padrão de saúde física e mental, incluindo a saúde sexual e reprodutiva. (2014, p. 1-2).
\end{abstract}

O conceito de violência obstétrica enquanto violência institucional é, por sua vez, também entrelaçado com as representações de gênero, tendo em vista que, além de as relações desiguais de poder envolverem médicos e pacientes, as parturientes são negligenciadas como sujeitos de direitos, principalmente no contexto sexual e reprodutivo, em uma relação hierárquica na qual a paciente é tratada como um objeto de intervenção profissional.

\footnotetext{
A violência institucional decorre das relações sociais marcadas pelo descaso com os aspectos humanísticos do cuidado, da rigidez hierárquica nas relações dos profissionais de saúde com os pacientes/clientes, das falhas no processo de comunicação, da mecanização do cuidado, do uso inadequado da tecnologia, do não compromisso dos profissionais com o processo de cuidar. (SOUZA, 2014, p. 42).
}

Neste estudo optou-se por sintetizar as categorias de violência obstétrica conforme proposta apresentada por D’Oliveira, Diniz e Schraiber (2002): negligência, abuso verbal, abuso físico e abuso sexual. Tendo em vista o dano potencial, bem como a relevância dada à violência psicológica pelas parturientes em seus relatos, optou-se por adicionar tal categoria àquelas já propostas pela literatura especializada. A partir do panfleto expositivo organizado pela Defensoria Pública do Estado de São Paulo (2013) sobre a violência obstétrica, bem como se considerando a literatura utilizada no decorrer deste estudo, elaborou-se a síntese abaixo.

No que concerne à negligência, os danos iatrogênicos a ela correlacionados referem-se a: abandono, negligência ou recusa de atendimento às mulheres que são percebidas como queixosas, descompensadas ou demandantes; negativa ou demora no atendimento à mulher em situação de abortamento; recusa da admissão em hospital ou maternidade (peregrinação por leito).

O abuso físico correspondente aos procedimentos que incidem sobre o corpo da mulher, que interfiram, causem dor ou dano físico (de grau leve a intenso), tais como: 
episiotomia sem necessidade clínica, manobra de $\operatorname{Kristeller}^{2}$, cesáreas eletivas ${ }^{3}$, exames de toque sucessivos, dolorosos e realizados por diferentes pessoas, soro com ocitocina ${ }^{4}$ para acelerar o trabalho de parto, privação de alimentos e bebidas, imobilização de braços e pernas, restrição da posição para o parto, intervenções sem anestesia, descolamento de membrana e/ou ruptura artificial da bolsa sem consentimento da mulher, "ponto do marido" (sutura da episiotomia maior que a necessária para fechar o corte a fim de estreitar a vagina com o escopo de que melhoraria a vida sexual para o parceiro), uso de fórceps sem indicação clínica, tricotomia, enema (lavagem intestinal), manobra de Valsalva (orientar a mulher a "trincar os dentes e fazer força); mulheres e/ou bebês que ficam retidos em estabelecimentos de saúde até que se resolva pendências com plano de saúde ou questões relacionadas ao pagamento; impedimento ou retardo no contato da mulher com o bebê após o parto.

O abuso verbal refere-se ao tratamento verbal de modo grosseiro, humilhante, brusco, antipático, áspero, repreensivo, ameaçador, uso de frases jocosas, xingamentos e insultos ridicularizando e humilhando a mulher. Além disso, nos serviços de aborto, as mulheres podem ser verbalmente abusadas, estigmatizadas e ter sua moral questionada.

$\mathrm{O}$ abuso sexual refere-se às ações que se destinam ao controle da sexualidade da mulher através do abuso da posição de poder e confiança, como assédio sexual, flerte, "cantadas", contatos físicos forçados, convites impertinentes, insinuações, incitações sexuais, mutilação da vagina, exames de toque sucessivos, dolorosos e realizados por diferentes pessoas, episiotomia, ponto do marido, laqueaduras ou histerectomias sem aviso prévio, sem esclarecimento e sem consentimento.

A partir de várias fontes de pesquisa, dentre as principais a Lei 11.340/2006 (Lei Maria da Penha), o Dossiê da Violência Obstétrica "Parirás com dor" (CIELLO et al, 2012), o Relatório Mundial sobre violência e saúde (OMS, 2002), estabeleceu-se o conceito de abuso psicológico como qualquer conduta que cause dano emocional ou prejuízo à saúde psicológica

\footnotetext{
${ }^{2}$ Manobra na parte superior do útero, durante as contrações do parto, visando empurrar o nascituro em direção à pelve a fim de acelerar o trabalho de parto. A OMS (1996) classifica a prática como ineficaz, sem evidência científica para utilização e usada de forma inadequada.

${ }^{3}$ A cesárea eletiva é aquela realizada sem necessidade clínica, podendo ser agendada e feita conforme a conveniência médica, antes mesmo do início do trabalho de parto, dissuadindo muitas vezes a mulher quanto à sua necessidade e também a coagindo.

${ }^{4}$ A ocitocina sintética (artificial) usada de maneira indiscriminada, apenas para acelerar o trabalho de parto, sem indicação correta e aplicada no soro da parturiente causa o aumento significativo das dores durante as contrações e, se não for controlada, pode causar sérias complicações para a mulher e o neonato, podendo levar desde a dor e sofrimento desnecessários ao aumento excessivo da frequência cardíaca da parturiente, além de causar dificuldades na oxigenação do bebê, bem como dano cerebral ao mesmo. A correção da dinâmica do parto com utilização de ocitocina é uma prática não recomendada pela OMS (1996).
} 
e à autodeterminação da mulher; diminuição, prejuízo ou perturbação ao seu pleno desenvolvimento; que tenha o objetivo de degradá-la ou controlar suas ações, comportamentos, crenças e decisões mediante ameaça, constrangimento, humilhação, manipulação, isolamento, vigilância constante, perseguição, insulto, chantagem, ridicularização, exploração, limitação do direito de ir e vir ou qualquer outro meio, qualquer tipo de discriminação em virtude da raça, etnia, idioma, histórico médico, crenças, preferências, estado civil ou situação conjugal, orientação sexual, número de filhos, status econômico e nível educacional da mulher; proibição injustificada de acompanhante ou autorização apenas para acompanhantes do sexo feminino, questionamento à mulher quanto à causa do abortamento (se intencional ou não), ameaça, acusação e culpabilização da mulher nos casos de abortamento, coação com finalidade de confissão e denúncia à polícia.

A violência obstétrica frequentemente culmina em danos físicos, psicológicos e sexuais em forma de violência institucional contra mulheres e contribui para a manutenção dos altos índices de mortalidade e neonatal no país, revelados como muito elevados se comparados aos países desenvolvidos, impedindo que o Brasil avance no cumprimento do compromisso internacional dos Objetivos de Desenvolvimento do Milênio (ODM) da ONU.

Nesse sentido, é imprescindível que as práticas obstétricas estejam de acordo com os níveis aceitáveis de interferência no corpo e saúde das gestantes, incluindo as intervenções físicas praticadas pelos profissionais de saúde na atenção obstétrica de forma a prevenir a ocorrência de potenciais danos à saúde e vida das parturientes. Desta forma, tomando por base tais reflexões problematiza-se no próximo item, a violência obstétrica a partir das formações médica e jurídica.

\title{
3 SIGNIFICANDO A VIOLÊNCIA OBSTÉTRICA FRENTE ÀS FORMAÇÕES MÉDICA E JURÍDICA: ERRO MÉDICO OU VIOLÊNCIA DE GÊNERO?
}

\begin{abstract}
Durante a lenta recuperação, diante de tanto maltrato [uma sucessão de procedimentos invasivos e perigosos, que resultaram em morte do bebê, perda do útero e infecção hospitalar generalizada], a única coisa que quero é morrer. Da minha vagina continua escorrendo pus, minha filha está morta e, além de tudo, agora sou estéril. Minha família, para consolar-me, me diz que não sou nem a primeira nem serei a última que passa por isso, que já vou me esquecer deste pesadelo, que me conforme. E é ali, no meio da dor física e moral, da raiva e da impotência, que me pergunto: e as que agora são meninas e um dia decidirão ser mães, vai acontecer a elas o mesmo que me aconteceu? Até quando vamos esperar para denunciar, falar, exigir? ${ }^{5}$ (Bunch et al., 2000, p. 117 apud DINIZ, 2001, p. 63).
\end{abstract}

\footnotetext{
${ }^{5}$ Depoimento da testemunha Carmen Cruz no "Tribunal Internacional de Direitos Reprodutivos como Direitos Humanos.
} 


\subsection{FORMAÇÃO MÉDICA}

A relação assimétrica que existe entre as mulheres e os profissionais da saúde revela uma desigualdade, tanto simbólica como real, que dificulta o exercício dos direitos fundamentais da mulher. Essa relação desigual desdobra-se de modo potencial quando configurada uma violência que, conforme Schraiber (2008, 1997), na área de saúde é determinada pela crise de confiança na relação médico/paciente, potencializada em virtude da fragilidade dos vínculos de confiança, a despersonalização do cuidado e o predomínio do uso de tecnologia como forma de interação, transformando o paciente em objeto de intervenção.

No contexto da assistência em maternidades, a paciente é duplamente objetificada: seu corpo é tomado como objeto de controle e domínio da medicina e como meio para se chegar a um fim - o bebê. Essa 'objetificação' traz em si aspectos ligados a uma ideologia de gênero, de dominação do corpo feminino como objeto da medicina enquanto “corpo reprodutor” (AGUIAR; D’OLIVEIRA, 2011, p. 88).

Essas questões revelam uma contradição concernente ao ensino médico, que se desdobra em uma dicotomia entre o ensino da medicina e o contexto real da saúde/doença da população (LUZ, 2013). Isso acontece porque o modelo de ensino médico não percebe necessariamente o doente na prática profissional, mas considera apenas a doença. Tal conduta é observada através do conhecimento médico esboçado apenas no retórico e na racionalização dos procedimentos, não cumprimento do direito de informação aos pacientes e autonomia na escolha dos métodos, fazendo com que a prática médica não utilize a informação como ferramenta fundamental para o exercício dialógico que embasa os relacionamentos interpessoais democráticos (SILVA, 2005). Nesse sentido,

\footnotetext{
Na posição de doutores de um saber, sobre um outro que é objeto, médicos destronam a posição terapêutica para ocupar um lugar que nos ensina como devemos viver. Aqui, constata-se de maneira inteligível o quanto o saber médico se articula ao poder disciplinar e normalizador. A ordem médica, assim compreendida articulada à microfísica do saber e poder, com seu olhar focado na doença e não na pessoa do doente, implica uma recusa e desqualificação da subjetividade e singularidade de cada fato clínico (TAVIRA, 2014, p. 1).
}

Assim, o discurso médico é concebido como o discurso da verdade, e seus profissionais aparecem como uma das autoridades mais importantes do nosso tempo. Isto tem consequências vitais, porque o discurso médico assume um poder institucional privilegiado, além da legitimação social para administrar e governar a vida. Sob essa perspectiva, sugere-se que a formação médica é um dos fatores que contribuem para disseminação da violência institucional nos serviços de saúde (D’OLIVEIRA; DINIZ; SCHRAIBER, 2002), tendo em vista o modo 
como se estruturam as relações de saber-poder entre profissionais em formação e as mulheres por eles atendidas; a baixa prioridade dada à aprendizagem da ética e de aptidões associadas à comunicação; e as formas tradicionais de treinamento de residentes são considerados elementos associados à reprodução desse fenômeno. (HOTIMSKY, 2009).

O modo como os profissionais desvalorizam a dor diante do sofrimento das parturientes é uma forma comum de abuso de poder e de negação da subjetividade das mulheres nas práticas obstétricas, fazendo parte de um padrão de violação de direitos humanos que tende a ser naturalizado e repassado aos alunos de medicina enquanto modelo a ser replicado durante a atenção ao parto, contribuindo assim, para a perpetuação do fenômeno (HOTIMSKY, 2009).

Além disso, na formação médica, os alunos desenvolvem estratégias visando incrementar seu "senso de competência". Nesse sentido, frequentemente as mulheres não são consultadas ou sequer informadas acerca dos procedimentos ou práticas realizadas, sendo seus corpos transformados em objeto de treinamento (HOTIMSKY, 2009). A objetificação do corpo feminino também pode ser vislumbrada na prática médica através do não-respeito à dor física e o desconforto sentidos pela paciente ao submeter-se a determinados procedimentos e intervenções que são vistas como comuns aos que as executam (PEREIRA, 2004). Outrossim, os estudantes são treinados para manter distância emocional de seus pacientes, o que na prática dá margem a relações pouco empáticas dos profisssionais em relação a seus pacientes, naturalizando hierarquias sociais que caracterizam o campo médico, "coisificando" os corpos das mulheres que são vislumbradas como objetos de treinamento ${ }^{6}$.

Nesse sentido, faz-se necessária a adoção de um novo paradigma médico em que se leve em consideração as recomendações baseadas na evidência empírica e as novas tendências nas relações entre profissionais e pacientes, postuladas a partir da centralidade do direito à informação e à decisão informada nas ações de saúde, pressupondo que a decisão deva ser compartilhada entre os envolvidos, ao invés de decidida de forma unilateral pelo profissional e

\footnotetext{
${ }^{6}$ A compreensão do corpo como objeto de estudo é arraigada nos serviços de saúde. Em pesquisa de tese realizada por Diniz (2001) na qual ela questiona uma enfermeira acerca do quantitativo de episiotomia realizada no hospital analisado, a mesma responde que é perto de $100 \%$ e afirma que os residentes precisam aprender e que as mulheres funcionam como material didático. A iatrogenia latente pode ser percebida por meio de um depoimento coletado por Diniz: "Então nós estávamos com os estagiários de vários países no CLAP (Centro Latinoamericano de Perinatologia, no Uruguai) assistindo um parto conduzido segundo as recomendações da OMS. Quando terminou, percebemos que um dos médicos estagiários continuava na sala e fomos ver o que ele estava fazendo. Ele tinha feito uma episiotomia depois do parto, que foi conduzido sem episio. E ele disse, na maior seriedade, que foi porque ele precisava treinar!" (2001, p. 102-103). Filia-se ao pensamento de Diniz de que não se pretende defender de todo a ideia de que os profissionais não treinem os procedimentos em pacientes reais, mas o evidente abuso de indicações parece evidenciar que o aprendizado do procedimento é secundário ao aprendizado de valores como o respeito à integridade física das pacientes. Ademais, a autonomia e informação da paciente devem ser sumárias e levadas em consideração antes da realização de qualquer procedimento.
} 
pela instituição que presta a assistência. (DINIZ, 2001).

De maneira semelhante, a problemática da desumanização no curso da formação jurídica corrobora para que práticas violadoras de direitos possam de algum modo permanecer impunes e silenciadas ou ainda não terem as sanções adequadas ou proporcionais à gravidade das violações de direitos cometidas.

\subsection{FORMAÇÃO JURÍDICA}

Desde a sua implementação, os cursos jurídicos no Brasil apresentaram como principal característica a transmissão de um ensino jurídico meramente reprodutor de normas, suprimindo-se o entendimento de suas bases e primando por, na melhor das hipóteses, formar exímios técnicos-legalistas, o que justificou o uso do termo "fábricas de bacharéis" para caracterizá-las. O modelo dogmático/positivista marca ainda o atual momento do ensino jurídico do país e não tem conseguido acompanhar as transformações sociais, políticas, culturais e econômicas pelas quais o país tem passado, negligenciando a formação de profissionais críticos e transdisciplinarmente embasados, habilitados a uma devida atuação perita nas diferentes instituições do sistema de justiça do país. Além disso, o ensino jurídico brasileiro é caracterizado na atualidade pela mercantilização do ensino superior e sua despolitização, integrado por conteúdos quase que exclusivamente tecnicistas e por uma cultura jurídica liberal, burguesa, individual, formalista e burocrática, por conseguinte, iatrogenicamente reproduzido na atuação dos operadores do direito que atuam nas mais diferentes instituições do Sistema de Justiça em nossa sociedade (MACHADO, 2005). Há um descompasso entre o país legal e o país real uma vez que o ensino do Direito excessivamente legalista e formalista não acompanha a realidade dinâmica e os anseios da sociedade contemporânea, o que o torna descontextualizado e consequentemente desacreditado frente aos jurisdicionados, consumidores finais da atuação profisssional em questão.

Nesse sentido, a resolução em série de conflitos marcadamente individualizados, visando apenas à demonstração quantitativa de produtividade, generalizando-se ou padronizando-se decisões com a colagem de ementários de jurisprudência, citações e seguindo modelos de peças em geral, sem qualquer reflexão crítica e sem que se avaliem as peculiaridades de cada caso concreto, ilustra bem a dificuldade que os atores do sistema de justiça possuem de significar novos fenômenos, como é o caso da violência obstétrica.

Essas ponderações relacionam-se à perspectiva positivista legalista do Direito através da qual os direitos são vislumbrados exclusivamente através da letra da lei, quando o mais adequado 
seria o reconhecimento de que a lei é somente o ponto de partida de toda interpretação, uma vez que:

[...] o juiz deve estar consciente de que as regras legais existentes não podem servir de limite à prestação jurisdicional. Ante situações novas, a busca de subsídios em regras ditadas para outras relações jurídicas tende a soluções conservadoras. Por outro lado, não reconhecer direitos sob o fundamento de inexistir previsão legal, assim como usar normas editadas para situações outras ou em diverso contexto temporal, nada mais é do que mera negação de direitos. [...] Se o fato sub judice se apresenta fora da normatização ordinária, uma resposta precisa ser encontrada, não só na analogia, nos costumes, e nos princípios gerais de direito, como ordena a lei civil, mas principalmente nos direitos e garantias fundamentais, que servem de base ao estado democrático de direito (DIAS, 2004, 24-25).

Nesse sentido, o exegetismo dos cursos jurídicos revela o premente distanciamento científico que impera nos currículos jurídicos exageradamente normativos com a mera transmissão e cobrança em concursos públicos de conteúdos genéricos, dogmáticos, desconectados da realidade atual e muitas vezes inaplicáveis à solução de problemas complexos na vida real. Tal pensamento tradicionalista no ensino do Direito vislumbra-se na aplicação de um modelo dogmático/positivista com um currículo fragmentado que abrange apenas uma concepção legalista, expressando o padrão jurídico normativo do Direito. Repousam aqui as bases de uma crescente judicialização de conflitos repetitivos ou ainda de conflitos contemporâneos sem sanções adequadas, sobrecarregando todo o Sistema de Justiça que, ao não dar respostas satisfatórias aos conflitos levados a juízo, os faz retornar ao Sistema, retroalimentando um ciclo vicioso crescente e interminável (GOMES, 2008)

Para Streck (2011), a formação desse senso comum teórico tem uma relação direta com o processo de aprendizagem nas escolas de Direito, uma vez que o ensino jurídico ainda continua preso às velhas práticas. Sob essa perspectiva, a problemática também se assenta no viés metodológico que, conforme proposto por Gomes (2008), se refere à falência no método clássico de ensino, sem liame entre teoria e prática com uma pedagogia tradicionalista por meio da qual o professor apresenta-se como mero expositor e o aluno, um simples receptor.

Esse modelo reflete-se de maneira mais contundente na praxe do ator jurídico, uma vez que, ao operar o Direito, o conjunto de práticas e valores desenvolvidos na formação profissional será agora aplicado socialmente, refletindo no seu papel civil. Nesse sentido, uma das grandes dificuldades encontradas em termos de educação (jurídica) na atualidade está associada à mantença de um paradigma inadequado diante de uma sociedade complexa. A chamada "crise dos paradigmas" conforme proposto por Streck (2011) e Machado (2005) não 
proporciona mais novas diretrizes e rumos para os problemas científicos da contemporaneidade, desdobrando-se em um conjunto de equívocos.

Por isso, Warat defende que o ensino do Direito exige o conhecimento de outros conceitos, advindos de outras áreas, evitando assim uma alienação atrelada exclusivamente a verdades pré-montadas segundo um paradigma já proposto, mas que não atende aos reais anseios da contemporaneidade, defendendo, portanto, uma pedagogia aberta, conectável com outras dimensões, fomentando a liberdade de pensamento, transformando alunos em partícipes dos processos de aprendizagem.

Desta forma, é premente a negligência jurídica consubstanciada a partir da hipossuficiência técnica dos agentes do sistema de justiça ${ }^{7}$ contribuindo para a legitimação de danos iatrogênicos que acometem a sociedade em geral, a exemplo do que ocorre quando se ajuízam e processam ações relativas à violência obstétrica.

\section{CONSIDERAÇÕES FINAIS}

A problemática em torno da violência obstétrica tem sido recorrente no cenário médico e jurídico brasileiro, sendo imbricada pelas próprias peculiaridades observadas durante ambas as formações acadêmicas.

De um lado, a relação assimétrica que existe entre as mulheres e os profissionais da saúde revela um ponto de estrangulamento, tanto simbólico como real, dificultando o exercício de direitos fundamentais das primeiras. Essa relação desigual desdobra-se de modo potencial quando configurada uma violência que, conforme Schraiber (2008; 1997), na área de saúde é determinada pela crise de confiança na relação médico/paciente, potencializada em virtude da fragilidade dos vínculos de confiança, da despersonalização do cuidado e do predomínio do uso de tecnologia como forma de interação, transformando o paciente em objeto de intervenção.

De outra banda, as iatrogenias advindas também das decisões são observadas nos danos imediatos em decorrência das decisões e consequentemente na descrença dos jurisdicionados quanto à atuação do poder judiciário. A busca por uma norma de forma dedutivista lógico-formal, típico do paradigma normativo-doutrinário que impera no Direito, principalmente no que tange às questões da contemporaneidade, culmina com o amordaçamento dessas mulheres.

\footnotetext{
${ }^{7}$ Para configuração da pesquisa, utilizamos esse termo para se referir aos advogados, juízes, desembargadores, promotores e defensores públicos.
} 
Apesar de mudanças significativas no que concerne aos textos legais discriminatórios, o que ainda se percebe são problemas ligados às assimetrias de gênero em termos de acesso à justiça, uma vez que a garantia de direitos não necessariamente se relaciona à existência de normas que expressamente discriminam as mulheres, mas estão mais relacionados com a devida aplicação das leis, em tese formalmente neutras, mas que na prática, ainda reproduzem efeitos discriminatórios quando da sua aplicação imperita (SEVERI, 2011).

Diante destas ponderações, fica evidente a necessidade de os operadores do sistema de justiça estarem tecnicamente habilitados para compreender as bases estruturais e históricas da violência de gênero atrelada às especificidades da violência obstétrica, uma vez que a hipossuficiência técnica diante da temática constitui um dificultador na promoção do acesso à justiça por tais mulheres, contribuindo para que estas não tenham um julgamento justo, ou seja, perito, para suas causas.

Nesse sentido, defende-se que a violência obstétrica como forma de violência de gênero deve ser difundida, sobretudo através de seu reconhecimento em decisões judiciais, uma vez que em função da condição de intensa vulnerabilidade durante a gestação, cada vez mais mulheres sofrem este tipo de violação, ainda pouco reconhecida.

Além disso, pontua-se que é imprescindível a adoção de um novo paradigma médico que leve em consideração as recomendações baseadas em evidência empírica e as novas tendências nas relações entre profissionais e pacientes, postuladas a partir da centralidade do direito à informação e à decisão informada nas ações de saúde.

Nessa esteira, conclui-se pela necessidade de capacitação continuada dos magistrados e demais operadores do direito para que possam compreender melhor a temática e assim aprofundar seus conhecimentos transdisciplinares a fim de que sejam proferidas decisões mais bem embasadas tecnicamente e que determinem sanções proporcionais à gravidade dos casos levados a juízo. Ademais, insta salientar a importância da capacitação continuada dos profissionais da área de saúde que contemple uma visão social e humanística de suas atuações, incluindo-se o reconhecimento de direitos dos pacientes, de modo a oferecer à parturiente um processo de atenção adequado no ciclo gravídico-puerperal.

É premente também a necessidade de divulgação do tema por meio de políticas públicas de prevenção, bem como a necessidade de conscientização da população em geral acerca do parto humanizado, para que as parturientes possam efetivamente reconhecer e passar a pleitear seus direitos, pois, infelizmente, o número expressivo de mulheres que sofrem violência 
obstétrica ainda não pode ser mensurado ou sequer inferido e/ou estimado através dos poucos casos que chegam aos tribunais.

\section{REFERÊNCIAS}

AGUIAR, Janaína Marques de. Violência institucional em maternidades públicas: hostilidade ao invés de acolhimento como uma questão de gênero. Tese (doutorado) Faculdade de Medicina da Universidade de São Paulo. Departamento de Medicina Preventiva. São Paulo, 2010. Disponível em: $<$ http://www.apublica.org/wpcontent/uploads/2013/03/JanainaMAguiar.pdf>. Acesso em: 02 nov. 2015.

AGUIAR, Janaína Marques de; D’OLIVEIRA, Ana Flávia Pires Lucas. Violência institucional em maternidades públicas sob a ótica das usuárias. Interface - Comunic., Saúde, Educ., v.15, n.36, p.79-91, jan./mar. 2011.

ARGENTINA. Lei $\mathbf{n}^{\mathbf{0}} \mathbf{2 6 . 4 8 5}$. Ley de protección integral para prevenir, sancionar y erradicar la violencia contra las mujeres en los ámbitos en que desarrollen sus relaciones interpersonales. Abril, 2009. Disponível em:< http://www.cnm.gov.ar/

LegNacional/Ley_26485_decreto_1011.pdf> Acesso em: 16 mar. 2015.

\section{BRASIL. Convenção Interamericana para Prevenir, Punir e Erradicar a Violência contra} a Mulher, “Convenção Belém do Pará”. Disponível em: $<\mathrm{http}$ ://www.unfpa.org.br/Arquivos/convencao_belem_do_para.pdf >. Acesso em: $21 \mathrm{dez}$. 2015.

CIELLO, Cariny et al. Parto do princípio. Mulheres em Rede pela Maternidade Ativa. Dossiê da Violência Obstétrica "Parirás com dor". Disponível em: $<$ https://www.senado.gov.br/comissoes/documentos/SSCEPI/DOC\%20VCM\%20367.pdf>. Acesso em: 10 dez. 2015.

DIAS, Maria Berenice. Conversando sobre justiça e os crimes contra mulheres. Porto Alegre: Livraria do Advogado Editora, 2004.

DINIZ, Carmen Simone Grilo. Entre a técnica e os direitos humanos: possibilidades e limites da humanização da assistência ao parto. Tese (doutorado) - Faculdade de Medicina da Universidade de São Paulo. Departamento de Medicina Preventiva. São Paulo, 2001.

D’OLIVEIRA, Ana Flávia Pires Lucas; DINIZ, Simone Grilo; SCHRAIBER, Lilia Blima. Violence against women in health-care institutions: an emerging problem. The Lancet, Vol 359, May 11, 2002. Disponível em: $<$ http://www.thelancet.com/pdfs/journals/lancet/PIIS01406736(02)08592-6.pdf>. Acesso em: 02 nov. 2016.

GOMES, Luiz Flávio. A crise (tríplice) do ensino jurídico. 2008. Disponível em: < http://www.egov.ufsc.br/portal/sites/default/files/anexos/29134-29152-1-PB.pdf >. Acesso em: 09 jan. 2017. 
HOTIMSKY, Sonia Nussenzweig A violência institucional no parto no processo de formação médica em obstetrícia. Trabalho proposto para apresentação no I ENADIR Encontro Nacional de Antropologia do Direito Universidade de São Paulo - 20 e 21 de agosto de 2009

LUZ, Madel Therezinha. As instituições médicas do Brasil. 2. ed. - Porto Alegre: Rede UNIDA, 2013.

MACHADO, Antonio Alberto. Ensino jurídico e mudança social. Franca: Edunesp, 2005.

SILVA, Artenira da Silva e. Personalidades REconstruídas em aula de aula: um olhar psicológico sobre o ensino médico. 1. ed. São Luís: SENAC, 2005. v. 1. 126p

SILVA, Artenira da Silva; SERRA, Maiane Cibele de Mesquita. Violência obstétrica no Brasil: um enfoque a partir dos acórdãos do STF e STJ. Quaestio Iuris. vol. 10, nº. 04, Rio de Janeiro, 2017. pp. 2430-2457.

ORGANIZAÇÃO MUNDIAL DE SAÚDE. Relatório mundial sobre violência e saúde. Genebra, 2002. Disponível em: <https://www.opas.org.br/wpcontent/uploads/2015/09/relatorio-mundial-violencia-saude.pdf>. Acesso em: 04 nov. 2015.

instituiçôenção e eliminação de abusos, desrespeito e maus-tratos durante o parto em $<$ http://apps.who.int/iris/bitstream/10665/134588/3/WHO_RHR_14.23

_por.pdf>. Acesso em: 04 nov. 2015.

. Tecnologia apropriada para partos e nascimentos. Recomendações da Organização Mundial 1996.de Saúde. Maternidade Segura. Assistência ao parto normal: um guia prático. Genebra: 1996.

PEREIRA, Wilza Rocha. Poder, violência e dominação simbólicas nos serviços públicos de saúde. Texto Contexto Enferm 2004 Jul-Set; 13(3):391-400.

SÃO PAULO. Defensoria Pública do Estado de São Paulo. Violência obstétrica: você sabe o que é?. Escola da Defensoria Pública do Estado: São Paulo, 2013. Disponível em: $<$ http://www.defensoria.sp.gov.br/dpesp/repositorio/41/violencia $\% 20$

obstetrica.pdf $>$. Acesso em: 10 dez. 2015.

SCHRAIBER, Lilia Blima. O médico e suas interações: a crise dos vínculos de confiança. São Paulo: Hucitec, 2008.

No encontro da técnica com a ética: o exercício de julgar e decidir no cotidiano do trabalho em medicina. Interface - Comunic., Saude, Educ., v.1, n.1, p.123-40, 1997.

SEVERI, Fabiana Cristina. Direitos humanos das mulheres e a transversalidade de gênero no sistema de justiça. Revista de Estudos Jurídicos, a. 15, n. 22, 2011.

SOUZA, Karina Junqueira de. Violência institucional na atenção obstétrica: proposta de 
modelo preditivo para depressão pós-parto. 2014. 106 f. Dissertação (Mestrado em Saúde Coletiva) - Pós-Graduação em Saúde Coletiva, Universidade de Brasília, Brasília, 2014.

STRECK, Lenio. Hermenêutica Jurídica e(m) Crise: uma exploração hermenêutica da construção do direito. 10 a ed. Porto Alegre: Livraria do Advogado, 2011.

TAVIRA, Larissa V. O nascimento da clínica em Foucault. Um poder-saber sobre a vida. (Em)Cena - Saúde Mental em Movimento. Palmas: Ceulp/Ulbra, 2014

VENEZUELA. Ley Orgánica sobre el derecho de las mujeres a una vida libre de violência. Março, 2007. Disponível em: < http://venezuela.unfpa.org/sites/lac.unfpa. org/files/pub-pdf/Ley_mujer\%20(1)_0.pdf>. Acesso em: 16 mar. 2016.

VENTURI Gustavo; GODINHO Tatau. Mulheres brasileiras e gênero nos espaços público e privado. São Paulo: Sesc/Fundação Perseu Abramo, 2010. Disponível em: <

http://csbh.fpabramo.org.br/sites/default/files/pesquisaintegra.pdf $>$. Acesso em: 02 nov. 2015. 